3. Sood S, Sharma R, Gupta S, Pathak D, Rishi S. Neuroaspergillosis in an immunocompetent patient. Ind $J$ Med Microbiol, 2007; 25(1): 67-9.

4. Sharada DM,Arunkumar G, Vandana KE,Rao PS. Sinoorbital aspergillosis in a diabetic patient. Ind $\mathrm{J} \mathrm{Med}$ Microbiol, 2006; 24(2): 138-40.

5. Siddiqui AA, Shah AA, Bashir SH. Cranicerebral Aspergillosis of Sinonasal origin in immunocompetent patients. Neurosurgery, 20004; 602-13.

6. Segal BH; Walsh TJ. Current approaches to diagnosis and treatment of invasive aspergillosis. Am J Respir Crit Care Med, 2006Apr 1; 173(7): 707-17.
7. Schwartz S, Ruhnke M, Riband P, Corey L, Driscell T, Cornely OA, et al. Improved outcome in central nervous system aspergillosis; using voriconazole treatment. Blood, 2005; 106: 2641-5.

8. Walsh TJ; Anaissie EJ; Denning DW; Herbrecht R; Kontoyiannis DP; Marr KA; Morrison VA; Segal BH; Steinbach WJ; Stevens DA; van Burik JA; Wingard JR; Patterson TF Treatment of aspergillosis: clinical practice guidelines of the Infectious Diseases Society of America. Clin Infect Dis, 2008 Feb 1; 46(3): 327-60.

9. Boucher HW; Groll AH; Chiou CC; Walsh TJ. Newer systemic antifungal agents: pharmacokinetics, safety and efficacy. Drugs, 2004; 64(18): 1997-2020.

\title{
A case of Dengue fever complicated by acute pancreatitis
}

\author{
Kodisinghe SK, Fernando AHN \\ National Hospital of Sri Lanka, Colombo, Sri Lanka \\ Correspondence to: Dr.Kuleesha Kodisinge (skkodisinghe@gmail.com)
}

\section{Introduction}

Dengue is the most rapidly spreading mosquitoborne viral disease in the world. In the last 50 years, the disease incidence has increased by 30 -fold. It has also become a pandemic, involving the urban and rural populations. Worldwide, an estimated 50 million dengue infections occur annually. The SouthEast Asian region and the Western Pacific region bear $75 \%$ of the current global disease burden. Reported case fatality rates for the South-East Asian region is approximately 1\%(1). Year 2010 had 34097 cases of Dengue in Sri Lanka resulting in 241 deaths. In 2011, 7948 cases of dengue were reported up to mid June, with 69 deaths (2).

We report of a case of Dengue fever complicated by acute pancreatitis. Review of PubMed and Cochrane databases revealed very few reported cases of acute pancreatitis in Dengue (3-6). In South Asia, this is the second reported case of Pancreatitis in Dengue infection (6).

\section{Case report}

A 35 year old male army soldier was transferred to National Hospital of Sri Lanka with fever of 4 days duration with upper abdominal pain. On admission there was flushing, icterus, hepatomegaly with epigastric and right hypochondriac tenderness and bilateral pleural effusions and ascites. There was no bleeding and the patient was haemodynamically stable. On the second day after transfer, his conscious level deteriorated and the GCS was 7/15. There was thrombocytopenia and the dengue IgM antibody was positive. Non contrast CT scan of the brain revealed mild cerebral oedema and the liver functions were of a hepatitis pattern.

He was managed in the Intensive Care Unit with the routine fluid management protocol for dengue, and the anti-liver failure regimen along with N-Acetyl Cysteine. Routine capillary blood sugar measurements detected hyperglycaemia, which was managed with insulin. 
By the $8^{\text {th }}$ day of the illness there was laboratory evidence of resolution of the hematological and hepatic diseases and the patient was fully conscious and rational. Yet there was persistent fever with upper abdominal pain and tenderness. The serum amylase at this point was found to be elevated to $1137 \mathrm{U} / 1$ which subsequently rose to $1800 \mathrm{U} / 1$. Serum calcium was low at $2.0 \mathrm{mmol} / 1$. Acute pancreatitis was confirmed by USS abdomen. The pancreatitis was managed conservatively with an uneventful recovery by the $13^{\text {th }}$ day of the illness.

\section{Discussion}

Dengue virus (DEN) belongs to the genus Flavivirus, family Flaviviridae, comprising of four distinct serotypes (DEN-1 to 4). "Asian" genotypes of DEN2 and DEN-3 are frequently associated with severe secondary dengue infections (1). Severe complications of dengue infection such as liver failure, encephalopathy, disseminated intravascular coagulation, myocarditis, acute renal failure, and haemolytic uraemic syndrome are rare but have been noted to be more frequent in recent epidemics (7). Pancreatitis in this patient could only be attributed to Dengue fever as there was no evidence of causal relationship to alcohol, gallstones, hypertriglyceridaemia or medications. Leptospira agglutination on lysis test done on day 12 of the illness gave an equivocal titre of 1:100 but there was no rising titre when the test was performed 2 weeks later.

Upper abdominal pain is usually found in dengue infection and in most instances is due to hepatitis. This case highlights the possibility of acute pancreatitis as a cause for upper abdominal pain in dengue fever.

\section{References}

1. Dengue Guidelines for Diagnosis, Treatment, Prevention and Control: New Edition. WHO/TDR. 2009 (Document WHO/HTM/NTD/DEN/2009.1)

2. Distribution of reported DF/DHF by week, Sri Lanka 20042011 (up to 17/06/2011). Sri Lanka Epidemiology Unit. (Accessed June 28, 2011, at http://www.epid.gov.lk/pdf/ DHF_2011/weekly DF-DHF GRAPH FOR 2004-2011-1706-2011.pdf.)

3. Derycke T, Levy P, Genelle B, Ruszniewski P, Merzeau C. Acute pancreatitis secondary to dengue. Gastroenterol Clin Biol, 2005 Jan; 29(1): 85-6.

4. Chen TC, Perng DS, Tsai JJ, Lu PL, Chen TP. Dengue hemorrhagic fever complicated with acute pancreatitis and seizure. J Formos Med Assoc, 2004 Nov; 103(11): 865-8.

5. Jusuf H, Sudjana P, Djumhana A, Abdurachman SA. DHF with complication of acute pancreatitis related hyperglycaemia: a case report. Southeast Asian J Trop Med Public Health, 1998 Jun; 29(2): 367-9.

6. CN Wijekoon, PWMCSB Wijekoon Case report. Dengue hemorrhagic fever presenting with acute pancreatitis. Southeast Asian J Trop Med Public Health, 2010 July; 41(4): 864-6.

7. Gurugama P, Garg P, Perera J, Wijewickrama A, Seneviratne SL. Dengue viral infections. Indian Journal of Dermatology, 2010; 55: 68-78. 